\title{
VIII.
}

\section{Jean Pauls philosophischer Entwicklungsgang.}

Ton

\section{Dr. Josef Mïller in Nünchen.}

Vorbemerkung.

Einen Dichter als Philosophen einzuführen, kann vielleicht von vorn herein Anstoss erregen. Was speciell Jean Paul betrifft, so hat z. B. 0. Flügel in seinem Werk: "Die spekulative Theologie der Gegenwart, kritisch beleuchtet" (Cöthen bei Schulze) S. 133 an Ebrard getadelt, dass dieser sich in einer philosophischen Frage auf Jean Paul berufen hat; das sei "Missbrauch der Autorität". Ich dächte jedoch, dass in der Philosophie weder von Missbrauch noch Gebrauch des Autoritätsprincips gesprochen werden sollte. Ist ein Gedanke richtig, dann ist es gleichgiltig, ob derjenige, der ihn zuerst gefasst, Poet oder Fachmann gewesen, sowie es gleichgiltig ist, welcher Nation oder Gesellschaftsklasse er angehörte; ist er falsch, dann kann der grösste Ruhmeskranz der Fachphilosophie ihn nicht zum richtigen stempeln. Ob Jean Paul Philosoph gewesen, das muss sich aus dem Inhalt seiner philosophischen Arbeiten ergeben und niemand, der diese kennt, wird ihm das Prädikat eines grossen Denkers versagen. Jean Paul war Philosoph nicht nur in dem Sinn, in welchem jeder ordentliche Dichter als Menschenkenner, Psycholog und Beobachter Einblicke in das Welt- und Geistesleben und Regeln für das Charakterstudium gewinnt, sondern er hat eine Fïlle theoretischer Abhandlungen, den Bereich der 
Philosophie im weitesten Umfang betreffend, geschrieben, die einer Beachtung der Fachphilosophen und der philosophiegeschichtlichen Forschung nicht entzogen werden dürfen. Dass diese Beachtung doch so wenig oder so spät erst erfolgte, hatte mehrfache Gründe: Einmal sind unsere Litteraturhistoriker, denen zunächst die Abwandlung der Dichter naturgemäss zusteht, der Philosophie fast durchweg abhold, die Philosophen dagegen haben wiederum Scheu, den Spiel- und Irrgarten der Poesie zu betreten - Männer wie Haym, Kuno Fischer sind seltene Ausnahmen -; J. Paul speciell hatte den Nachtheil, selbst in seinen poetischen Schöpfungen einer schnellen unverdienten Missachtung zu verfallen, sodass die philosophischen Arbeiten erst recht der Vergessenheit anheimfielen; seine Biographen: Spazier, Otto, Förster hatten keine philosophische Ader und liessen seine Denkprodukte abstrakteren Inhalts mehr oder weniger bei Seite, so dass ein grosser Theil, namentlich der früheren Arbeiten, noch ungedruckt ist. Paul Nerrlich, der sich in neuerer Zeit viel mit Jean Paul beschäftigte, hatte wieder einen dem des Dichters viel zu entgegengesetzten philosophischen Standpunkt, als dass dieser bei einem so subjektiven Historiker, wie es Nerrlich ist, gerechte Würdigung finden konnte. Was aber allen bisherigen Schriftstellern zur Last fällt, ist, dass sie nicht einmal die Beischaffung und das Studium des Quellenmaterials sich angelegen sein liessen, so dass die Arbeit ganz von vorn begonnen werden muss.

Ich habe in einem zweimaligen Aufenthalt in Berlin den gesammten ungedruckten Nachlass des Dichters eingehend studirt und stïtze vornehmlich auf diese unmittelbaren Quellen meine Ausführungen. Alle aus dem Nachlass bisher veröffentlichten Schriften sind fehlerhaft und unzuverlässig (was bei der schlimmen Handschrift des Dichters und seiner Methode der Abkürzungen, wie er sie in seinen Tagebüchern und Studienheften anwendete, kein Wunder ist.) Bei den Citaten habe ich daher genaue Revision der gedruckten Texte beobachtet (diese im Zusammenhang werde ich anderswo vornehmen). ${ }^{1}$ ) Vieles ist von mir überhaupt erst erschlossen und bisher unbekannt

1) S. Siuphorion 6. Jabrgang, 3. u. 4. IIcft, 7. Jahıg. 1. Heft: „Jean Pauls litterarischer Nachlass." 
gewoseu. Erst nach lirschliessung des ganzen J. Paul war eine Geschichte seiner philosophischen Entwicklung möglich, wie ich sic hier grebo.

Ich habe in meinem Buch „Jean Paul und seine Bedeutung lür die Gegenwart" und in meiner Dissertationsschrift: „Die Seelenlehre Jean Pauls" ") freilich auch die Philosophie des Dichters dargestellt, aber nur in der Reife seiner Entwicklung, nicht in ihrem $W^{T}$ erden und Entstehen. Insofern dient gegenwärtige Arbeit meinem Hauptwerk als Ergänzung, nach Umständen auch zur Berichtigung. Natürlich sind auch alle ähnlichen Schriften über Jean Paul miteinbezogen. Ganz bei Seite blieb jedoch die Aesthetik Jean Pauls. Dies ist die einzige Sparte seiner Philosophie, die bisher allgemein gewürdigt wurde. An dem Verfasser der „Vorschule für Aesthetik" konnte natürlich kein Kunstphilosoph des Jahrhunderts vorübergehen. Eben deshalb blieb dieser Theil hier weg. Was ich dazu zu sagem hatte, habe ich anderswo genügend gesagt.

\section{I.}

Die Schulzeit bis zum Universitätsstudium.

Wir müssen, um den späteren Jean Paul und seinen Geistesgang zu verstehen, bis in die fernste Tiefe seiner Kindheit zurückgehen; denn schon da-stossen wir auf Momente, die für die ganz eigenartige Entwicklung seines Genies von schwerwiegendem Einfluss waren. Jean Paul genoss keinen geregelten Schuluntẹrricht, obwohl oder weil sein Vater selbst Lehrer war. Kaum hatte er nämlich die Schule in Joditz zu besuchen angefangen, so veranlasste ein unbedeutender Vorfall (ein Rencontre mit einem Schüler) den Vater und Pfarrer, seinen Sohn aus der Bauernschule zu nehmen und selbst zu unterrichten. Wie dieser Unterricht ausgefallen, das berichtet der Dichter selbst in „Wahrheit aus meinem Leben“, 2. Vorlesung. „Vier Stunden vor- und drei Stunden nachmittags gab unser Vater uns Unterricht, welcher darin bestand, dass er uns bloss auswendig lernen liess Sprüche, Katechis-

2) Beide 1894 bei Dr. H. Lüneburg in München erschienen; dasselbst auch 1900 „Jean-Paulstudien“. 
mus, lateinische Wörter und Langes Grammatik. Wir mussten die langen Geschlechtsregeln jeder Deklination samt den Ausnahmen nebst der beigefügten Beispielzeile lernen, ohne sie zu verstehen. Ging er an schönen Sommertagen über Land, so bekamen wir so verdammte Aufgaben wie Panis, piscis zum Hersagen für den nächsten Morgen auf, von welchen mein Bruder Adam, dem der ganze lange Tag kaum zu seinem Herumrennen und Kindereien aller Art zulangte, gewöhnlich kein Achtel im Kopf übrig hatte. Denn nur selten erlebte er das Glück, so köstliche Deklinationen wie scamnum oder gar wie cornu in der Einzahl, wovon er allerdings jedesmal wenigstens die lateinische Hälfte herzusagen wusste, aufgegeben zu bekommen." Der Autor knüpft an diesen Bericht die humoristische Bemerkung: „Eigentlichen Schullehrern ist sogar diese Methode anzuempfehlen, weil bei keiner so viel Zeit und Mühe zu ersparen ist als bei dieser wahrhaft bequemen, wo der Zögling am Buch den Vikarius oder Adjunktus des.Lehrers. oder dessen Curator absentis erhält und wie ein kräftiger Hellseher sich selber magnetisirt. Ja, dieses geistige Selberstillen der Kinder lässt eine solche Ausdehnung zu, dass ich mir getraue, durch die blosse Briefpost ganzen Schulen in Nordamerika vorzustehen, oder in der alten Welt fünfzig Tagreisen entfernten, indem ich meiner Schuljugend bloss schriebe, was sie täglich auswendig zu lernen hätte, und einen unbedeutenden Menschen hielte, dem sie es hersagte, und ich genösse das Bewusstsein ihrer schönen geistigen Fastensonntage Reminiscere." Dann fährt er fort: „Im Speccius übersetzte ich auf Befehl viel vom Anfang ins Lateinische mit der Freude, womit ich jeden neuen Zweig des Lernens erstieg und abbeerte; die letzte Hälfte desselben bracht' ich von selber ins Latein, aber ohne einen Korrektor der Fehler zu finden. Die Colloquia in Langes Grammatik weissagt' ich mir deutsch aus Sehnsucht ihres Inhalts; aber mein Vater liess mich in Joditz nichts ïbersetzen. In einer lateinisch geschriebenen Grammatik der griechischen Sprache studirt ich durstig und hungrig das Alphabet und schrieb am Ende ziemlich griechisch, was nämlich die Handschrift anlangt. Wie gern hätt' ich mehr gelernt und wie leicht! Wenn nicht der Leib, doch der Geist einer Sprache fuhr leicht in mich hinein." 
Geschichte, Naturgcschichte, Gcographic, Arithrnctik und Astronomie sowic Rechtschreibung ficlen in dieser sonderbaren Privatschule, die bis zum 12. Jahre währte, vollständig aus und mussten durch spiitore Selbstbildung und "brockenweise" Lektüre nachgeholt werden. Den Mangel eines systematischen Unterrichts in diesen Füchorn konnte Jean Paul zeitlebens nicht ganz verwindęn. $\mathrm{Na}$ montlich wirkte bei der nachher einbrechenden Flut ungeregelter licktïre der Mangel logischer Zucht und Schulung. für die Geistesentwicklung und den Stil Jean Pauls schädlich, und der Ausfall des anschaulichen Unterrichts, die mangelnde Uebung des Auges und Raumsinns hatten zur Folge, dass der Dichter, wie er selbst gesteht, nie im Stande war, durchwanderte Gegenden kartographisch sich zurechtzulegen oder für Geometrie und Mathematik überhaupt Interesse zu gewinnen. Die Geschichte schätzte er nur einerseits nach ihrer erhabenen und elevirenden Seite, besonders als Schauplatz grosser Persönlichkeiten - daher. sein Enthusiasmus für Plutarch - andrerseits als Fundgrube von Seltsamkeiten, die er für seine humoristischen Partien verwerten konnte. Nach diesen Gesichtspunkten trug er alles zusammen; um die thats ächliche Gestaltung einer Staaten- und Volksgemeinschaft, um sorgfältige Kritik und Akribie in Prüfung des Materials kümmerte er sich wenig. Es ist haarsträubend, was für Daten der Dichter aus den verrufensten Quellen oft aus zehnter Hand rein zum $Z$ weck einer poetischen, besonders witzigen Ergötzung in seinen Sammelbüchern aufgehäuft und in seinen Werken am schicklichen Platz eingeflochten hat. Die Orthographie endlich glaubte er selbständig aus rein apriorischen Erwägungen zu gestalten und abzuändern das Recht zu haben.

Interessant ist aus der ersten Epoche Jean Pauls noch die Bemerkung seiner Autobiographie:

„In der künftigen Kulturgeschichte unseres Helden wird es zweifelhaft werden, ob er nicht vielleicht mehr der Philosophie als der Dichtkunst zugeboren war. In frühester Zeit war das Wort Weltweisheit - jedoch auch ein zweites Wort, Morgenland mir eine offene Himmelspforte, durch welche ich hineinsah in lange, lange Freudengärten. Nie vergess' ich die noch keinem 
Menschen erzählte Erscheinung in mir, wo ich bei der Geburt meines Selbstbewusstseins stand, von'der ich Zeit und Ort anzugeben weiss. An einem Vormittag stand ich als ein sehr junges Kind unter der Hausthür und sah links nach der Holzlege, als auf einmal das innere Gesicht: ich bin ein Ich! wie ein Blitzstrahl vom Himmel vor mir fuhr und seitdem leuchtend stehen blieb, da hatte mein Ich zum ersten Mal sich selber gesehen und auf ewig."

Durchdringende Geistesschärfe und machtvolle Phantasie die beiden Grundfaktoren des Jean Paul'schen Genius - äusserten sich" schon in dieser ersten Zeit in auffallender und glückverheissender $W^{\top}$ eise, erstere in den Fortschritten des Schülers trotz des dürftigen Unterrichts, in der Fertigkeit, ganze Predigten ohne Stocken wiederholen zu können, in überraschenden Genieblitzen, die den Vater öfter erstaunen machten, letztere in wunderlichen Spielen, Erfindung von Spielzeug und eig'enen Buchstaben, in dem Sinn für Tonkunst und Poesie, namentlich romantischer Art. Die Frühreife seines Geistes zeigt sich auch in der Neigung des Kindes, jeden Papierfetzen mit seinen Gedanken anzufüllen. In einem Blatt der „Ironien“ aus dem Jahr 1787 bemerkt Jean Paul, dass er „Bücher und Buchstaben fast zu gleicher Zeit zu schreiben anfing“. ("Wahrheit aus Jean Paul's Leben" herausg. v. Otto und Förster 3, 7 Note).

Bei der Uebersiedlung der Pfarrfamilie von Joditz nach Schwarzenbach a./S., 9. Jan. 1776, kam der fast dreizehnjährige Knabe zum erstenmal in eine ordentliche Schule. Der Lehrer, der ihn dort zu behandeln hatte, war der Rektor Werner, "ein schöner Mann mit breiter Stirn und Nase, voll Feuer und Gefühl, mit hinreissender Naturberedsamkeit, voll Fragen und Gleichnissen und Anreden à la Pater Abraham, übrigens ohne alle Tiefe weder in Sprachen noch in andern Wissenschaften. Indes half er der Armuth auf dieser Kehrseite durch einen Kopf voll Freiheitsrede und -Eifer $a b$; seine Zunge war der Hebel der kindlichen Gemüther. Sein Grundsatz war, aus der Grammatik nur die allernotwendigsten Sprachformen - worunter er bloss die Deklinationen und Konjugationen verstand - lernen zu lassen und dann ins 
Lesen oines Schriftsteller's ïberzuspringen. Paul musste sogleich den Sprung hoch über Langes Colloquia hinweg in den Cornelius thun, und es ging. . . Bald daraul wurde auch dic griechische Grammatik mit dem Erlernen der Deklinationen und der nötigsten Zeitwörter angefangen und ohne weiteren Aufenthalt bei der Grammatik sofort ins Neue Testament zum Uebersetzen übergesetzt. II'erner, der oft im Feuer der Rede sich selber so lobte, dass er über seine eigene Grösse erstaunte, hielt seine fehlerhafte Methode für eine originelle, ob sie gleich nur eine Basedow'sche war; aber Pauls niegendes Fortschreiten wurde ihm ein neuer Beweis. Etwa ein Jahr darauf wurden einige wenige Deklinationen und Zeitwörter aus Danzens lateinisch geschriebener hebräischer Grammatik zu einer Schiffbrücke zum Ersten Buch Mosis zusammengehangen, dessen Anfang - gerade die Exponirschwelle junger Hebräer den ungebildeten Juden zu lesen verboten war." (Wahrh. a. m. Leben. 3. Vorl.)

Denselben Rektor Werner, seinen ersten ordentlichen Lehrer, hat Jean Paul im „Titan" mit vielem Humor, aber wenig Pietät als den "Schachtelmagister" Wehmeier verewigt. Wer das 17. Kapitel des Romans mit der Charakteristik Werners in der Autobiographie zusammenhält, wird diese meine Konjektur nicht anzweifeln. Jean Paul verlor den Respekt vor seinem Lehrer nicht nur wegen dessen eigenlobigen Rodomontaden, welche Schwachheit Jean Paul mit so unvergleichlichem Sarkasmus gegeisselt hat, sondern auch weil er einmal bemerkte, dass Werner eine gedruckte Uebersetzung unter dem Uebersetzungsbuch liegen hatte. Doch hätte Jean Paul immerhin seinem Pfadführer in drei fremde Sprachen dankbarer sein sollen; der rasche Fortschritt des Schülers war in der That Resultat einer guten Methode im Gegensatz zu der elenden seines Vaters; nur war der Erfinder derselben nicht Basedow, sondern Ratich, dessen Ideen Locke in seinen „Gedanken über die Erziehung der Kinder" (1690) verwerthete. In neuerer Zeit wurde die psychologische Sprachmethode (an Stelle der abstrakt-logischen) vervollkommnet durch Hamilton, Jacotot u. A. (s. meine "Pädagogik und Didaktik auf modern-wiss. Grundl." $\S 28$ und Anhang). Für wie werthvoll Jean Paul diese Methode 
erkannte, dafür ist Beweis, dass er sie praktisch stets befolgte. „Ich machte nie viele Umstände mit einer fremden Sprache, sondern las ein Buch, das gerade darin geschrieben war, dann gab sich der Rest." Vita-Buch (Wahrh. v. J. P. L. II. 65).

Sehr wichtig war für diese Zeit, dass der junge Kaplan Völkel

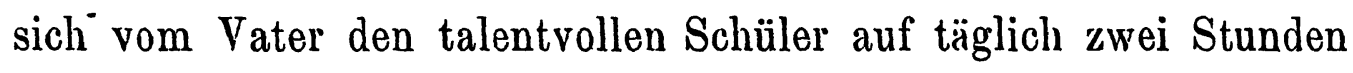
ausbat, um ihm Unterricht in Philosophie und Geographie beizubringen. Den Erfolg beschreibt er folgendermaassen: „In der Philosophie las Völkel oder eigentlich ich ihm vor die Weltweisheit von Gottsched, welche mich bei aller Trockenheit und Leerheit doch wie frisches Wasser erquickte durch die Neubeit. Darauf zeigte er mir auf einer Landkarte - ich glaube von Deutschland - viele Städte und Grenzen; was ich aber davon behalten, weiss ich nicht und such' es bis heute vergeblich in meinem Gedächtnis. Ich getraue mir, zu beweisen, dass ich unter allen jetzt lebenden Schriftstellern vielleicht der bin, welcher von Landkarten das Wenigste versteht. Ein Atlas von Landkarten trüge statt des Himmels des mythologischen für mich eine Hölle, wenn ich sie in meinen Kopf überzutragen hätte; was in letztem von Erdbeschreibung an Städten und Ländern etwa hangen geblieben, ist das Wenige, was mir unterwegs angeflogen auf dem geographischen Lehrkursus, welchen, theils die Postwagen statarisch, theils die Hauderer kursorisch mit mir nahmen, um mich in gutem Gymnasium-Deutsch auszudrücken."

„Desto melur dank' ich dem guten Kaplàn für seine Anleitung zum deutschen Stil, welche in nichts bestand als in einer Anleitung zur sogenannten Theologie. Er gab mir nämlich den Beweis ohne Bibel zu führen auf, z. B. dass ein Gott sei oder eine Vorsehung u. s. w. Dazu erhielt ich ein Oktavblättchen, worauf nur nit unausgeschriebenen Sätzen, ja mit einzelnen Worten, durch Gedankenstriche auseinandergehalten, die Beweise und Andeutungen aus Nösselt, Jerusalem und anderen standen. Diese verzifferten Andeutungen wurden mir erklärt, und aus diesem Blatt entfalteten sich, wie nach Goethes botanischem Glauben, meine Blätter. Mit Wärme fing ich jeden Aufsatz an, mit Lohe hörte ich auf; denn immer kamen ins Ende das Ende der Welt, des Lebens, die Freuden des 
Himmels und all das Uobormaass, das der jungen Rebe in ihrem warmen lrühling entquillt, und das orst im IIerbst \%u etwas (ieistigem zoitigt. ... Meine wöchentlichen Ausarbeitungen gäbe ich jetıt für keine der jetzigen hin, sie mögen noch so sehr die Wclt bilden; denn jene bildeten noch weit mehr mich selber, besonders da ihre Gegenstïnde meinem Trieb zum Philosophiren die Schranken aufthaten und ihn sich ausrennen liessen; ein Trieb, der schon vorher aus meinem engen Kopf auslaufen wollte in ein schmales Oktavbüchlein, worin ich das Sehen und Hören logisch zu ergründen suchte und dachte und woraus ich meinem Vater etwas erzählte, der mich so wenig tadelte and missverstand als ich."

Jetzt sind wir bereits bei Jean Paul dem Philosophen angelangt. Schon sehen wir seine spekulirende Kraft energisch sich regen; aber noch fehlt der Stoff des Wissens, an dem sich dieselbe wirksam bethätigen könnte - jener Versuch, Sehen und Hören a priori zu ergründen, konnte natürlich nichts Taugliches zu Tage fördern bald sollte auch diesem Mangel in überreichem Maasse abgeholfen werden. Freilich nicht, so lange der Vater lebte. Denn bis dahin blieb dessen Bibliothek ein verbotener Baum, dessen Früchte nur verstohlen in Abwesenheit des Regenten genossen werden konnten. (Jean Paul erzählt, dass er sogar in einer leeren Empore auf dem Bauch liegend während der Predigt des Vaters einen Roman gelesen habe.)

Da kam ihm ein Mann zu Hilfe, der den entscheidendsten Eiufluss auf den jungen Studenten machte dadurch, dass er ihm seine reiche Bibliothek überliess und seinem Bildungsstreben in freundschaftlichster Weise, besonders nachdem der Vater 1779 gestorben war, mit Rath und That an die Hand ging. Es war der damalige Pfarrer Vogel in Rehau. An Stelle des Vaters, der seiner geistigen Entwicklung fast nur hemmend in den Weg trat, sich nicht einmal um die Fortschritte des Sohnes kümmerte (Wahrh. a. J. P.'s Leben 3,6), wurde ihm Vogel ein väterlicher Freund und Berater. "Ich bin Ihnen viel schuldig“, schrieb J. Paul am 27. Mai 1781, „es ist mein Glück, Sie kennen gelernt zu haben.“ Vogel versorgte ihn mit der theologischen, philosophischen und 
belletristischen Litteratur, wie sie die zweite Hälfte des 18. Jahrhunderts zu Tage förderte und befriedigte so endlich den lechzenden Durst, den er in der "geistigen Saharawüste" des Vaterhauses so lange ungestillt lassen musste. Aus den gelesenen Büchern machte sich Jean Paul Excerpte, durch die wir über den Gang seiner Lektüre genau unterrichtet sind. Die hervorragendsten Werke philosophischen oder verwandten Inhalts aus dieser Periode sind: nach den Excerpten vom Jahre 1778: die allgemeine deutsche Bibliothek; die allgemeine theologische Bibliothek; Gellerts moralische Vorlesungen; Hutcheson, Unsere Begriffe von Schönheit und Tugend; Das Grab dess Aberglaubens (Leipzig bei Metzler); Young, Vom Menschen; Nicolai, Das Leben und die Meinungen des Herrn Magisters Sebaldus Nothanker. Vom Jahre 1779: Schütz, Lehrbuch zur Bildung des Verstandes und Geschmacks; Briefe zur Beförderung des Geschmacks an einen jungen Herrn vom Stande (Leipzig und Basel 1764); Die Leiden des jungen Werther; Jerusalems Betrachtungen über die vornehmsten Wahrheiten unserer Religion; Wielands goldener Spiegel; Thomas Abbt, Vom Verdienste; Briefe an eine deutsche Prinzessin über verschiedene Gegenstände aus der Physsik und Philosophie, Leipzig 1773; Der Philosoph für die Welt, von Engel; Theorie der schönen Künste und Wissenschaften von Justus Riedel, Jena 1667; Neuere Apologie des Sokrates oder Untersuchung der Lehre von der Seligkeit der Leiden, von Joh. Aug. Eberhard, 1779; Versuch einer biblischen Dämonologie, von Semler; Mendelsohn's Pbädon und philosophische Briefe; Wielands Deutscher Merkur; Auserlesene Bibliothek der Neuesten deutschen Litteratur; Ephemeriden der Menschheit oder Bibliothek der Sittenlehre, Politik und Gesetzgebung 1776; Leipziger Musenalmanach.

Vom Jahre 1780: Lavater's Physiognomik, Sulzer's Vermischte Schriften, Betrachtungen über die Natur, von Bonnet; Musäus; Physiognomische Reisen; Deutsches Museum; Rousseaus Emil; Eberts Naturlehre für die Jugend; Kosmologische Unterhaltungen für die Jugend; Tellers Wörterbuch für das Neue Testament; L.essings Erziehung des Menschengeschlechts; Die vornehmsten Wahrheiten der natürlichen Religion, von Samuel Reimarus; dessen Allgemeine Betrachtungen über die Triebe der Thierc; Zimmer- 
In anns Aussichten in die Ewigkeit; Asmus von Claudius; Fergusons Grundsiitze der Moralphilosophie, übersetzt von Garve; Bonnets Philosophische Untersuchung der Beweise für das Christenthum; Hartleys Betrachtungen über den Menschen; Kants Betrachtungen über das Gefühl des Schönen und Erhabenen; Stur'z' Schriften, Feder's Logik und Metaphysik; Beccarias Abhandlung von Verbrechen und Strafe; Sulzers Allgemeine Theorie der schönen Künste; Popes Werke; Hippels Lebensläufe; Francis Bảcons Moralische, politische und ökonomische Versuche; Feders Untersuchungen über den menschlichen Willen.

Aus 1781: Isak Iselin, Ueber die Geschichte der Menschheit, Semlers Untersuchungen über den Kanon; Herders Aelteste Urkunde des Menschengeschlechts; Lichtenbergs Schrift Ueber Physiognomik, wider die Physiognomen, Göttingisches Magazin der Wissenschaften und Litteratur; La nouvelle Heloise par Rousseau; Zimmermann, Ueber die Einsamkeit; Tiedemanns Untersuchungen über den Menschen; Eberhards Allgemeine Theorie des Denkens und Empfindens. (Genaueres mit Auszügen s. Euphorion, Bd. VI. H. 3, S. 556-573.)

Von den Auszügen, die Jean Paul aus diesen Werken machte, sind nach der religiösen Seite interessant die rationalistischen gegen die Gottheit und Genugthuung Christi, Ewigkeit der Hölle und andere Dogmen gerichteten, welche die allmähliche Abwendung Jean Pauls von der Orthodoxie bekunden, dann die philosophischen Themate wie: Von Ideen - wie unsere Seele und unser Leib an einander gekettet sind - was Empfindung genannt wird - die Verschiedenheit der Sinne - wie die Seele denkt - die Begriffe von körperlichen Substanzen - was Schönheit ist. - innerliches Gefühl ist nicht unmittelbar Quelle des Schmerzes - Wohlgefallen und Missfallen entstehen aus der Vergesellschaftung der Begriffe - ein inneres Gefühl setzt angeborne Ideen nicht voraus - vom Schlafen und Träumen - vom Grossen und Erhabenen - vom Witz Widerlegung der Newtonschen Meinung von der Art und Weise, wie uns dunkle Körper sichtbar werden - Spinozistische Gottheit u.s. w. (Erörterung darüber habe ich bereits in der Veröflentlichung von Jean Pauls Nachlass gegeben.) 
Gleichzeitig mit den Excerpten begann Jean Paul auch selbständige Aufsätze über Materien, die ihn interessirten, als „Uebungen im Denken" niederzuschreiben. Sie beginnen im September 1779 und reichen bis Anfang 1781. Das erste Heft (im Ganzen sind es drei) trägt das Motto aus Engels "Philosophie für die Welt": "Schon hienieden ist die Weisheit an himmlischen Freuden reich, und wäre sie's nicht, warum säh'n wir aus ihrem Schoosse so ruhig allen Eitelkeiten der Welt zu?" Förster hat in "Wahrh. a. J. P.'s Leben“ 3, 66. 67 nur die Titel angeführt, in der 3. Gesammtausgabe Bd. 34 eine Skizze gegeben.

Die Sammlung der Aufsätze beginnt mit einer Untersuchung „Wie unser Begriff von Gott beschaffen sei“. Gott zu denken, müsste man unendliche Kräfte haben. Um Gott einigermaassen vorzustellen, nehmen wir alle geistigen Vollkommenheiten, die wir an uns kennen und drängen sie in ein Bild zusammen und dies nennen wir den Begriff von Gott.

Der zweite Aufsatz handelt „Von der Harmonie zwischen unseren wahren und irrigen Sätzen". Der Irrthum als solcher werde nicht immer eingesehen. Wir verknüpften Wahres und Falsches gemischt. Man müsse also Nachsicht mit dem Fehlenden haben; er irre in der Meinung, Wahrheit zu erkennen.

Die dritte Untersuchung führt den Titel: „Ein Ding ohne Kraft ist nicht möglich". Die Kraft gebe den Grund und die Möglichkeit des Seins. Hier ist Leibnizianischer Einfluss zu spüren:

Die vierte will aus rein spekulativen Gründen beweisen, dass ein "Perpetuum mobile" möglich sei. Die Antwort Eulers in unserem Jahrhundert fiel bekanntlich anders aus.

Die fünfte bringt „Allgemeines über Physiognomien“. Jean Paul dringt auf empirische, reiche Beobachtung; sie allein könne Grundlage zu haltbaren Theorien über das Thema werden.

Die sechste enthält „Unsere Begriffe von Geistern, die anders als wir sind".

Die siebente ist interessanter; sie untersucht, "Wie sich der Mensch, das Thier, die Pflanze und die noch geringeren Wesen vervollkommnen". Den Thieren wird Unsterblichkeit verheissen 
und in phantastischer $W$ eise ein Fortschritt zu höheren Formationen postulirt, auch die Pflanze, welcher Jean Paul (wie später Fechner, wohl auf Anregung Jean Pauls) ein schwaches Gefühl zuschreibt, worde „molir als Pflanze werden, aber Thier nicht". Selbst die Jinge, "die unter den Pflanzen sind" - Jean Paul nennt sie bezeichnender Weise nicht Körper - seien Seelen, Monaden und würden noch ungeahnte Kräfte entwickeln; denn wozu sollten sie sonst geschaffen sein? Der Einfluss Jeibnizens ist auch hier stark.

Der achte Aufsatz "Ueber die Religionen in der Welt" fasst die einzelnen Religionen als Abbild der jeweiligen Kulturstufe und nationalen Eigenthümlichkeiten eines Volks, giebt ihnen demnach nur relative Wahrheit. Ein immer höherer Fortschritt sei anzunehmen.

Der neunte hat das Thema: „Jeder Mensch ist sich selbst Maassstab, wonach er alles misst". Es wird das Glück, aber auch die Täuschung dargelegt, die darin liegt.

Der zehnte handelt „Ueber Narren und Weise“ - ein Lieblingsthema des Dichters. Es ist eine Grundidee Jean Pauls, dass ein Gran Narrheit zum unverfälschten Menschenthum gehöre. Ein Narr sei oft nur ein verstimmtes Genie. Die Grenzen von Weisheit und Narrheit liefen in einander. Etwas ganz anderes sei Dummheit; diese habe mit Weisheit nichts gémein. Das wird höchst geistreich und scharfsinnig nach allen Beziehungen auseinandergesetzt. Vgl. Berliner Ges. Ausg. 62, 238-245.

In einer von Förster in "Wahrh. aus J. P.'s Leben" nicht abgedruckten Bemerkung zu diesen Arbeiten stellt Jean Paul die Willensfreiheit in Frage. Der Geist könne auch ein automatum spirituale sein. Den Grund unseres Handelns in den inneren freien Willen verlegen, sei keine Erklärung. „Du willst dieses, weil du es willst" - ist ein identischer Satz. Nun ist.allemal wieder die Frage: Warum? warum du dieses Wollen willst? und so fort ins Unendliche." (Auch von Schopenhauer geltend gemacht.) Also müsse der Grund ausser uns liegen in der Kette von Vorstellungen und Folgen, die bis ins fernste All sich verzweigen. Diese Stelle ist besonders wichtig, weil dem späteren Jean Paul die Willensfreiheit als unantastbare Thatsache der Selbstgewissheit gilt. Auch hier ist wahrscheinlich Leibniz'scher Einfluss bemerkbar. 
Diesen Aufsätzen sind Bemerkungen beigefïgt, von denen wir die auf philosophische Materien bezüglichen hier aus „Wahrh. u.s. w.“ 3, 67-95 mitteilen, wobei wir nicht zu vergessen bitten, dass es sich um Produktionen eines 16-18jährigen Jünglings handelt. „Die Menge, die Verschiedenheit der Empfindungen, die wir durch einen Sinn erlangen, verhält sich wie die Feinheit desselben. Das Auge bietet uns eine erstaunliche Menge von Empfindungen dar, welche diejenigen, die wir durchs $\mathrm{Ohr}$ erhalten, weit übertreffen. J)er Geruch scheint zwar unter dem Geschmack zu sein, aber er ist es nur, weil dieser vor jenem geübt wird. Durchs Gefühl erlangen wir die wenigsten von einander verschiedenen Empfindungen, weil es der gröbste Sinn ist."

„Jede Idee ändert sich durch die Länge der Zeit, durch öfteres Vorstellen derselben. Ich denke keinen Gedanken in meinem ganzen Leben, davon der eine wie der andere wäre. Ich kann mir keinen Begriff zweimal vorstellen - weil der eine nicht wie der andere ist. Die Seele ist der Veränderung ebenso wie andere Dinge unterworfen. In jeder Sekunde leidet oder wirkt die Seele in jeder wird sie anders - und eben deshalb auch ihre Wirkung, das Vorstellen."

"Dieser Einwurf ist schon hundertmal aufgewärmt und widerlegt worden; und jetzt kommt man wieder mit ihm." " Dies ist die Sprache mancher, die lieber nachbeten als untersuchen. Ein solcher Nachtspruch soll sogleich einen ganzen Einwurf entkräften. "„Dieser Einwurf ist hundertmal aufgewärmt worden"“ - kann sein; aber dies zeigt an, er ist niemals widerlegt worden. Man hat so etwas gegen ihn gesagt; aber es reicht nicht zu. Daher kommt ein anderer, trägt eben diesen Einwurf mit in die Augen fallenden Farben vor, um aufmerksam zu machen. Ich halte den Menschen für zu gut, als dass ich glauben könnte, er vertheidige eine Sache, von deren Falschheit er überzeugt ist. Wenn jemand etwas, was schon widerlegt sein soll, wieder aufwärmt: so zeigt dies an, die Sache ist gar nicht, oder wenigstens nicht für diesen widerlegt worden."

"Es ist eben nicht leicht, ein System zu machen. Entwerler viele zusammen - in langer Zeit - machen sich ein System, so 
wio das theologische entstand - oder ein Genic bildet sich sellsst cius, wie die meist on philosophischen. Bcide Fälle legen die Schwierigkeit, die damit verbunden ist, deutlich an den Tag. /Es ist allemal leichter, einen Satz zu verstehen, von ihm überzeugt zu soin, auch ihn zu erfinden - als ihn in Verbindung mit anderen zu bringen - ja ganze Ideenreihen mit einander zusammenzupassen. ${ }^{3}$ ) Dies letzte kann bloss der, cler viel überdenkt, dessen Einbiluungskraft wirksam genug ist, um ihm sogleich die fernere Verbindung eines mit dem anderen $z u$ zeigen, aber auch eingeschränkt genug, um ihn in Deberdenkung vieler Sätze durch keine Nebenideen zu stören. Das erste fehlt oft dem Kalten - dem Mann - und das letzte schadet dem Jüngling. Beide Eigenschaften vereint geben den, der ein System machen kann. - Es ist mit den Systemen eine eigne Sache. Nichts ist unserer denkenden Natur mehr gemäss, als Wahrheiten im Zusammenhang zu denken, nichts freut uns mehr; denn hier ist die grösste Anstrengung des Geistes mit Vergnügen, das aus der vereinten Mannigfaltigkeit kommt, verbunden - allein nichts kann uns a uch mehr irre führen, als eben dieses. ${ }^{3}$ ) Denn wir stellen uns dann die Dinge nicht so ganz vor, wie sie sind, sondern wie wir sie in unser System hinein haben wollen - wir schnitzeln und formen so lange an dem Ding, bis es in unsere Ideenreihe hineinpasst."

„Diese Bemerkungen . . . müssen immer mit Einschränkung - und oft mit Ausnahmen - verstanden werden. Ein Satz ist dann nicht mehr Wahrheit, wenn man seine Allgemeinheit über die Grenzen ausdehnt." .

"Manche theologische Sätze, die der Aufgeklärtere für falsch hält, haben ihren Nutzen, ihren mannigfaltigen Nutzen bei geringen und minder erleuchteten Leuten. Sie sind Sporen zu gewissen Handlungen, die nicht geschehen würden, wenn man jene vermisste. In der. Welt ist Wahrheit und Irrthum so weise vertheilt, wie Sturm und Sonnenschein. Du verwirfst gewisse Sätze, die unwahr sind, aber sieh zu, ob du an ihre Stelle wahre setzen kannst, die

3) Von mir gesperrt gedruckt. 
cben den Nutzen bringen wie die falschen. Vielleicht bringt ein Irrthum nützlichere Folgen als eine Wahrheit an seiner Stelle versteht sich bei solchen, die ihn glauben. In Gottes bester Welt ist kein Irrthum ohne nützliche Folgen - und wo ein Irrthum ist, ist er's nicht umsonst, ist er an dem Orte besser als eine Wahrheit."

"Lass dem Unwissenden einen Irrthum, von dem er sich nicht zu überzeugen vermag; und dring' ihm keine Wahrheit auf, deren Beweis er nicht einsieht! Schenke ihm einen leichten Irrthum und quäl' ihn nicht mit schweren Wahrheiten! Sieh' allzeit, was deinem Bruder frommt! Ermiss die Güte seiner geglaubten Sätze nicht nach den Beweisen derselben, sondern nach ihren guten oder bösen Folgen! Der Weise liebt Wahrheit als Wahrheit, weil sie seinen Verstand ergötzt; der Unweise, weil sie ihm gefällt und ihm nützt. Nimmst du ihm das letzte weg, so hat er gar nichts. Denu das erste lässt sich nicht an seine Stelle setzen, weil er kein Weiser ist."

Damit im Zusammenhang steht die folgende, erst von mir aufgefundene Stelle der "Uebungen": „Wir sollen hier nicht weise werden, aber den Trieb bekommen, es einmal zu werden. Gottes Absicht hier in diesem Leben ist nicht, uns durch das reine Jicht der Wahrheit zu erleuchten, sondern nur, durch einen Schimmer derselben den wissbegierigen Geist nach einem Vergnügen anzulocken, das in einer anderen Welt unsere grösste Wollust ausmachen wird. Wollust gebiert Ekel, reine Wabrheit ist für uns nicht, weil sie der Thätigkeit des rastlosen Geistes Grenzen setzt."

Jean Paul mahnt, den (namentlich religiösen) Irrthum bei Niederstehenden zu schonen, 1. aus objektiven Erwägungen und sofern er grösseren Nutzen haben kann, 2. weil er subjektiv nicht durch die schwer zu .verstehende und für Grobdenkende verhängnissvolle Wahrheit zu ersetzen wäre. Ueberhaupt sei volle und unzweifelhafte Wahrheit hienieden nicht zu erreichen.

„Die Worte drücken nie das ganz aus, was man fühlt. Sie geben nur einen Umriss. Wen heftiger Affekt drängt, (der) findet nic lis Wurte, die seinen Seelenzustand hinmalten. Sie sagen nur, dass etwas da sei, aber nicht, was und wie es da sei. Nur der, welcher gleich gestimmt ist, fühlt das nämliche dabei - aber 
or fïhlt daun nicht bloss das, was dasteht, er fühlt auch noch, was der andero nicht ausdrïcken konnte. Er malt das Gemälde aus, las der andere nur durch schwache Umrisse gezeichnet hat. ..." "Wir begreifen gar nichts von Geistern. Die Kräfte eines Goistes - ihre Entwicklung - in was für einem heiligen Dunkel ist dies noch verhüllt? Wir spielen immer mit leeren Worten und glauben die Sache erhascht $z a$ haben, wenn es nur ihr Schatten ist. Was sind die Schranken eines Geistes? Wie.kommen einem Geist als Geist Schranken zu? - Ich bin mir ein unerforschliches 1)ing. 'Ich bin mir unbekannter, als alles, was mich umgiebt. Ich schaudere, wenn ich so ungewohnte Dinge fühle, wenn ich mich cinmal selbst erblicke. Sind wir denn immer bestimmt, ausser uns selbst herumzuirren, um zu suchen, was wir in uns schon haben? - Eben diese äusseren Dinge, die den Endzweck haben, uns uns selbst fühlen zu lassen, bewirken gerade das Entgegengesetzte, werfen uns aus uns selbst hinaus. Wir werden dadurch mehr Neigung als Gedanken - man vergebe mir Dunkelheit, wo Licht nicht möglich ist - und eben dadurch ungeschickt gemacht, uns selbst zu betrachten. Es sind mir merkwürdige Augenblicke, wenn ich mich selbst sehe."6

„Jedes Gute oder Böse, das uns betrifft, modifizirt sich nach unserer jedesmaligen Empfänglichkeit. Eben diese Freude schmelzt den einen in Wehmuth und treibt ihm Freudenthränen aus dem Auge und begeistert den anderen zur lärmenden Fröhlichkeit. Der vorige Zustand vermischt sich mit dem jetzigen auf eine bewunderungswürdige Art und schattirt ihn gleichsam. Dasselbe Unglück stürzt den einen in Verzweiflung, entflammt den andern zur Wuth, und lässt einen dritten in Starrheit und Unbeweglichkeit hinsinken oder einen andern heisse Thränen weinen. Wir fühlen eine Sache, wir geben den Ton an, nach dem wir gestimmt sind. Eine Metapher, die viel sagt." (Eine Vorahnung der Herbart'schen Apperception.)

„Es ist falsch, wenn man glaubt, ein Philosoph brauche kein starkes Gedächtniss zu haben. Wer selbst schon gedacht und bemerkt hat, wie schwer es ist, die feinen Gedanken sich nicht entwischen zu lassen, wird sich wundern, wie dem Philosophen 
Gedanken nicht entgehen, die man Mühe hat zu fassen, die so fein sind, dass sie ein scharfsinniges Auge kaum bemerkt. Der Philosoph hat ein ebenso gutes Gedächtniss wie der Geschichts schreiber; beide machen nur nicht gleiche Anwendung davon. Das Gedächtniss der Philosophen nimmt nur solche Dinge auf, die ... den Verstand interessiren. Dinge, die wenig zu denken geben, z. B. Zeitrechnungen, manche unbedeutende Geschichte des Vaterlandes u. s. w., - dies alles merkt es nicht; es hat wichtigere Sachen zu behalten. Eigentlich merkt man nur das, was man merken will, denn dies hat allemal den grössten Eindruck auf uns und wird deswegen auch viel leichter behalten. Es giebt aber verschiedenen Geschmack und ebendeswegen verschiedenes Gedächtniss. ${ }^{4}$ ) Jeder spricht dem das Gedächtniss ab, der nicht das behält, was er selbst behält. Aber er sollte bedenken, dass, wenn der Andere nicht gerade das merkt, er doch etwas merke. Die Gedächtnisse sind überhaupt weniger im Grad als vielmehr in der Art unterschieden. Der hat also das grösste Gedächtniss, der gegen alles am reizbarsten ist ${ }^{4}$ ) und der das geringste, der überall unempfindlich ist. Daher kommt das starke Gedächtniss der Jünglinge und das schwache der Greise."

Diese Erörterung klingt so stark an Herbarts Psychologie an, dass man hier die Geburtsstätte der letzteren suchen müsste, wäre nicht die Kenntnissnahme dieser Studien Herbart unmöglich gewesen. Jedenfalls aber hat unser Dichter dem verwandten Geist stark, vorgebaut und es ist anzunehmen, dass Herbart durch Jean Paul's philosophische Schriften und die zahlreichen Excurse seiner poetischen Werke bedeutend angeregt wurde. Herbart citirt bekanntlich J. Paul oft, besonders in der Pädagogik. Sehr interessant ist auch die folgende Erörterung:

„Es ist schwer, Gedächtniss und Einbildungskraft zu unterscheiden. Die Grenzlinien, wo's eine anfängt oder das andere aufhört, sind $\mathrm{zu}$ fein gezeichnet. So viel ist gewiss: Gedächtniss ist nie ohne Einbildungskraft. Ich kann mich keiner Sache erinnern, oline zugleich das Bild derselben wenigstens dunkel in der Seele zu haben. Und ist dies nicht Wirkung der Einbildungskraft?

i) Vón mir gesperrt gedruckt. 
Auch ist Binbildungskraft nie ohne Gedächtniss. Denn von allen möglichen Bildern, dio jeno zusammengesetzt, ist der Stoff aus der Natur genommen, den das Gedächtniss an die Hand giebt. Es ist möglich, dass das Ganze dieses nie in der Natur existirt hat; aber seino Theile sind doch dagewesen. Einbildungskraft thut nichts wciter, als zusammensetzen; nichts aber schafft sie. Sie ist ein Töpfer, der wohl dem Thon allerlei Gestalten giebt, aber ihn nicht hervorbringt. Einbildungskraft würde also nicht-sein, wenn Gedächtniss nicht wäre. Ueberhaupt scheint's mir, dass alles Gedächtniss bloss Einbildungskraft ist, und dass diese bloss es sei, die jenes giebt. Die Erinnerung ist nichts als die Bemerkung der Aehnlichkeit oder Unähnlichkeit der gegenwärtigen Sache mit dem Bilde in der Seele.) Und was ist die sogenaunte memoria localis anderes, als die Vergegenwärtigung dagewesener Bilder? Wenn das vermeinte Gedächtniss wirken soll, so müssen zwei Bilder von einer Sache in der Seele vorhanden sein, die man mit einander vergleicht und aus deren Aehnlichkeit mit cinander man schliesst, dass eines schon vorhanden war. Also ist bei jedem Gedächtniss ein Urtheil.) Die Einbildungskraft hat nur allzeit ein Bild vor sich. Ihre Absicht ist nicht, zu bemerken, dass es schon da war; sie nimmt gar keine Rücksicht auf die Zeit. 'Dieser hat viel Einbildungskraft, aber kein Gedächtniss.' Das ist kein Einwurf gegen mich. Ich kann eben dasselbe Vermögen der Seele bei dem einen Objekt üben und beim anderen ungebraucht lassen. So ist es beim Poeten. Eine Kraft äussert sich nicht bei allen Gegenständen auf dieselbe Art; sie wirkt hier stark, dort schwach. Es sind aber nicht zwei Kräfte." Ebenso bezeichnet Jean Paul in dem Aufsatz "Ueber die natürliche Magie der Einbildungskraft" aus 1795 (dem Quintus Fixlein beigedruckt), Gedächtniss für nichts als eingeschränktere Phantasie." Es beziebe sich auf die räumlichen und zeitlichen Verhältnisse gleicher Bilder. (Jean Paul berücksichtigt nur das unmittelbare Gedächtniss.)

Indem Jean Paul Erinnern als Bemerken, Vergleichen, also Urtheilen, der Form- und Bildungskraft, die mit dem Ideenmaterial gleich dem Töpfer freithätig schaltet, gegenüberhält, hätte er beide doch als verschiedene, wenn auch eng verbundene Funktionen der 
Secle auseinanderhalten und niclit confundiren sollen (beide setzen iibrigens eine dritte Kraft, das Behalten der Ideen, voraus); es ist ferner richtig, dass grosses Gedüchtniss bei schwacher Einbildungskraft vorhanden sein kann; man kann sogar sagen, dass wenigstens rücksichtlich der Treue und Zuverlässigkeit beide in umgekehrtem Verhältniss stehen. Der Poet wird selten ein guter Berichterstatter sein. Der Schlussgedanke Jean Pauls ist falsch; denn wer starke Einbildungskraft hat, der übt sie nicht nur bei einige n Gegenständen, sondern sie drängt sich ihm überall und bei allen Objekten verfälschend vor, ist also der Erinnerung antagonirend. Dabei braucht man nicht beide Kräfte als Vermögen in alt-scholastischem Sinn d. h. als gesonderte Geistesfächer auscinanderzuhalten.

Im 6. Heft der Excerpten S. 137 habe ich zwei Quellen gefunden, aus denen Jean Paul diese nicht ganz klar ausgedrückte Theorie des Gedächtnisses geschöpft hat mit theilweiser Umbildung derselben. Die erste ist ein Aufsatz der „Auserlesenen Bibliothek der neuesten deutschen Litteratur 1778 " S. 166 und von ihm ist das Excerpt genommen: „Wenn die Ideen, die durch Veranlassung anderer Ideen in der Seele erneuert werden, genau eben dieselben sind, die sie vormals gewesen, so ist das Ged'ächtn iss insbesondere wirksam, und das zu erkennen und die Ideen ebenso wiederzuformen und zu verbinden, wie sie vorher gewesen sind, das ist das Geschäft der Einbildungskraft. Wenn aber gar nicht darauf gesehen wird, ob die so herbeigeführten Ideen jetzt ebenso beschaffen sind, wie sie ursprünglich gewesen, da wir sie entweder von aussen bekamen oder sie uns selbst anfänglich formten, ... so bleibt nichts weiter übrig, als die Mitwirkung der Nerven nach dem Zusammenhang der Einstimmung und der Aehnlichkeit mit ihren Untergattungen und Verhältnissen, und die dadurch in uns erzeugten Ideen werden den Wirkungen der Phantasie überhaupt zugesprochen." Die unwillkürliche Ideenassociation ist hier ganz mechanisch aufgefasst und den "Nerven" zugesprochen (modern ausgedrïckt: den "Gehirnspuren“), was Jean Paul, dem der Materialismus stets ein Gräuel war, bei Seite liess; aus dem Vorangehenden aber erklärt sich Jean Pauls Identificirung von Gedächtniss und 
Einbildungskraft. Einbildungskraft ist hier in einem weiteren Sinn als lïhigkeit dor selbstthätigen Verknïpfung und Wiedererkennung der Jleen genommen, wodurch der Begriff dem der Erinnerungskralt angenilhert und mit ihm verschmolzen wurde. Die andere Stelle ist aus einem Referat über Tiedemanns Versuch über den Nenschen im „Deutschen Merkur" 1779, S. 182 genommen und litutet: „Die Einbildungskraft ist ein Theil des Empfindungsvermögens; sie erneuert nicht nur die Empfindungen des Gesichts, sondern auch die Sensationen des Ohrs, Geschmacks, Geruchs, Gefühls. . . Die Einbildungskraft betrachtet bloss die erneuerten Empfindungen, chne darauf zu sehen, ob sie schon ehemals dagewresen sind oder nicht; dies thut aber das Gedächtniss allemal. Bei jedem Akt des Gedïchtnisses findet sich also nothwendig ein Urtheil, bei den Akten der Einbildungskraft aber nicht. Sie beschäftigt sich nur mit Empfindungen. Die Erneuerung der Bilder ist auch lebhafter und darstellender als bei jenem. Ein gewisser Grad von Gedächtniss macht nicht Einbildungskraft, so wie umgekehrt ein gewisser Grad der Einbildungskraft nicht das Gedächtniss macht. Das Gedächtniss erhält nicht bloss das Empfangene, es erhält auch den Gedanken, dass es empfangen ist, die Zeit, den Ort, da es empfangen wurde. Von diesem allem gehört für die Imagination nichts." Die Bilder in fieberhaften Krankheiten würden sehr uneigentlich Phantasiebilder genannt, weil meist nur physiologischen Ursprungs, von Nervenerregungen herrïhrend. Hierher einschlägig ist auch noch eine Stelle aus Hippels „Lebensläufen in aufsteigender Linie, die in den Excepten des X. Heftes (1780) steht: „Wer keine Einbildungskraft hat, hat auch kein Gedächtniss. Ein grosses Gedächtniss kann die Urtheilskraft schwächen. Fassen und Behalten ist nicht dasselbe."

Durch diese Stellen kam Jean Paul zu dem Gedanken, Einbildung sei im Wesentlichen gleich Erinnerung, letztere sei nur noch mit dem Bemerken der A ehnlichkeit mit früheren Gedanken verbunden. Die eigentliche Kernfrage: wie überhaupt ein Wiedererkennen der Vorstellungen möglich sei, ist hier bei Seite gelassen. Es finden sich aber Stellen nicht fern von der damaligen Periode, in denen Jean Paul auch auf diese Frage eingegangen ist. 
So findet sich in den Aphorismen vom Jahre 1783 der Satz (Reimersche Ausgale 62, 36):

„Man verbessert, erhellt keine Vorstellung; denn die dunkle bleibt (nach dem Gedächtniss) stehen; sondern neben sie stellt man eine hellere. Bliebe also von jeder neuen Vorstellung ein Eindruck noch im Gehirn, so wäre die Zahl unendlich. Jede Vorstellung von derselben Sache ist bei jeder Wiederholung anders und wir merken sie nur wegen der Menge nicht."

Jean Paul nimmt also zur Erklärung der Erinnerung das Beharren der Vorstellungen im abgeschwächten „dunklen" Zustand im 'Leibniz'schen Sinn an; ein Verbessern der Vorstellungen ist also nur ein Uebertäuben und Vernachlïssigen der unrichtigen durch besser gedachte. Auch ist eine spïtere Vorstellung nie ganz gleich einer früheren (wegen des veränderten Bervusstseinszustandes und der neuen Associationen). Nur ein Schritt war noch nöthig: die Unterscheidung von bemerkt und unbemerkt in den bewussten Vorstellungen, um zu meiner Theorie des Erinnerns (s. mein „System der Philos." Kirchheim, Mainz 1898 S. 188-210) zu führen.

Interessant ist das Kapitel „Dunkle Vorstellungen“ (1790) bei Reimer $(63,104)$, in dem Jean Paul den „unbewusst schaffenden Geist" oder Instinkt als das Princip aller menschlichen wie thierischen Thätigkeit erklärt. Im Dunkeln, ohne die Begriffe zerlegt zu haben, fühlten wir, meint Jean Paul, die Widerlegbarkeit eines Satzes. Das Unberwusste - Jean Paul confundirt mit Leibniz unbewusst und unbemerkt - ist Jean Paul, wie er später im Companerthal sagt, das unentdeckte innere Afrika, der tiefere Quell aller bewussten Thätigkeit. Hier $(63,104)$ findet sich auch ein Hinausgehen über Leibniz, indem Jean Paul in einer Polemik gegen Sulzer die verworrene Vorstellung so gut wie die deutliche als eine einzige erklärt, also die Auflösung des Sinnlichen in undeutliches Geistige ablehnt. Nicht die Beleuchtung, sondern der Gegenstand werde geändert, wenn ich statt des verworrenen Anblicks eines Blatts die einzelnen Buchstaben deutlich erkenne und ihren Sinn enträthsele.

Die übrigen Bemerkungen zu den Aufsätzen sind wohl gleichfalls geistvolle Skizzen, die von der Beobachtungsgabe und dem 
jsychologischon Scharfblick des Dichters schon in dicsem Alter beredtes Zeugniss geben, beriihren aber nicht specifisch philosophische Matorien.

Zu Ostern 1779 meldete sich Jean Paul am Gymuasium zu IIof an und wurde nach eingehender Prüfung vom Rektor Kirsch sofort für die Prima reif befunden (der Vater liess ihn jedoch der Mittelklasse zuweisen) - gewiss ein glänzendes Zeugniss sowohl seiner Befähigung als auch - was gegen die alssprechenden Urtheile Spaziers $(1,113)$ and Nerrlichs (Jean Paul, sein Leben und seine Werke, S. 93) besonders betont werden muss - der Tüchtigkeit seines bei Werner genossenen Unterrichts. Hier war es auch, wo der junge Philosoph seinen ersten öffentlichen Triumph feierte und zwar gegen seinen Professor selbst. Der brave Conrector Rennebaum nämlich, dem der junge Student zugewiesen war, hatte die Gewohnheit, Disputirübungen abzuhalten, wobei die Rollen des Respondenten und Opponenten je einem Primaner zugetheilt waren. Paul war einmal Opponent und brachte den zur Diskussion gestellten Kirchenartikel durch die Schätze seines heterodoxon Wissens, die er aus der Vogel'schen Bibliothek geschöpft hatte, so in Frage, dass selbst der präsidirende Conrector, der auf solchen Widerspruch nicht gefasst und mit der rationalistischen Rüstkammer nicht halb so bekannt war als der Opponent, ihm nicht mehr aufhelfen konnte. Es blieb ihm nur übrig, dem Opponenten entrüstet Schweigen zu gebieten und ohne die sonst üblichen Lobspenden an die Kämpfenden den Saal plötzlich und unwillig zu verlassen. (Spazier 1. c. 1, 128 nach dem Bericht des Augenzengen 0tto.) Diese Begebenheit liess das Ansehen Jean Pauls bei den Commilitonen gewaltig steigen, brachte ihn aber bei der Bevölkerung in den Ruf eines Atheisten.

An den beiden Schlussakten der Schuljahre 1779 und 1780 wurde Jean Paul gewürdigt, die Festrede zu halten. Beide Reden sind noch erhalten: die eine "Ueber das Studium der Philosophie auf Schulen" steht im 3. Band des bei Reimer in Berlin 1838 erschienenen "Litterarischen Nachlasses" (63. Bd. der 1. Gesammtausgabe S. 5-16) und entwickelt die Wichtigkeit der Philosophie für sümmtlichè Wissenschaften. Jean Paul verficht den 
Satz, dass eine Encyklopädie der Philosophie schon auf den oberen Klassen des Gymnasiums als Vorarbeit für das akademische Studium getrieben werden müsse (was man staatlicherseits heute noch nicht einsehen will). Die andere, gehaltvollere Rede behandelt „Die Erfindung neuer Wahrheiten" und betont die Wichtigkeit des gediegenen ernsten Fortstrebens, aber auch die Schädlichkeit leichtfertiger Neuerung und Umstürzerei für alle Wissenschaften, besonders für Theologie und Philosophie. Auch der Theologie sei der Fortschritt nicht schädlich und diene nur zur Läuterung des Gotteserkennens; denn auch der Lessing'sche Fragmentist habe seinen Widerleger (nicht „Widersacher", wie Foerster, 3. Ges. Ausg. Bd. 34, S. 83 schreibt) gefunden. Jean Paul hatte jedoch, was Foerster nicht $\mathrm{zu}$ wissen scheint, Lessings Fragmente damals noch vicht gelesen, denn im Brief an Vogel vom 3. April 1781 bittet er erst um dieses Buch. (Reimer'sche Ausg. 63, 191, 192).

So sehen wir bereits den achtzehnjährigen Abiturienten und angehenden Candidaten der Philosophie und Theologie im Besitz eines ungewöhnlichen, meist durch Lectüre und Selbstdenken angeeigneten Wissens. Aber dieses Wissen war nicht geordnet; die Kenntnisse waren kunterbunt aus allen Fächern der Litteratur zusaınmeńgelesen; die verschiedenartigsten Ansichten kreuzten sich im Kopf des jungen Polyhistors und gestalteten sich nicht zur Einheit, zumal, die berathende Stimme eines erfahrenen Lehrers fehlte. - Den verwirrenden Eindruck, den diese Fülle zuströmenden Wissens auf den Geist des unerfahrenen Studenten machte, malt drastisch eine Studie, die Jean Paul im Mai 1781, also noch vor seiner Universitätszeit, abfasste: „Die Wahrheit - ein Traum" (Reimer 63, 254-262).

nMein Geist schwärmte ohne Leitfaden in einem Lande von Wahrheiten, Hypothesen und Wahrscheinlichkeiten heram. Ich dachte: Was ist denn das eigentlieh für ein Ding, das man Wahrheit nennt, welches in jedem Hörsaal, in jedem Tempel, in jedem Munde wiederschallt, um welches sich Tausende in Disputationen, in Büchern und Unterredungen zanken, um welches sich Tausende hassen and verfolgen und um welches Millionen mit Tigerwuth 
sind nicdergewüryt worden? Es ist ein Ding eigner Art, eine Sache, die jeder sucht, jeder zu finden glaubt und die Keiner gefunden hat, weil Jeder etwas anderes als der andere findet. Durstend cilt der Geist herum, die Wahrheit in ihrer göttlichen Gestalt zu umarmen, sich an ihrem Anblick zu laben, allein unbefriedigt geht cr hinweg, or findet nicht, was er suchte, oder ein Wahnbild muss scine Wünsche befriedigen. Wir wandeln in einem dunklen Lande. Ein Sterblicher entdeckt einen Schimmer, der 'seine Tritte auf dem schlïpfrigen Pfade dieses Lebens sichern soll. Allein ein anderer tritt näher und findet - es ist ein Irrwisch, der im Sumple - leuchtet und vergeht. . / Ich lese einen Zeno, Epikur, Moses, Spinuza, Paulus, Lamettrie, Leibniz, Bayle, Luther, Voltaire und noch Hunderte, und verirre mich in ein Labyrinth ohne Ausgang. Lauter Widersprüche, und Widersprüche zwischen grossen Geistern. Der, der mit Adlerblick den Gang der Wahrheit bis in ihre geheimsten Höhlen verfolgte, hat sich geirrt, und ich Kurzsichtiger, der ich kaum im Stande bin, die nächsten Gegenstände um mich herum zu erkennen, sollte entscheiden, welcher von beiden Scharfsinnigen recht gesehen habe! . . 0, Vater der Wahrheit, bist du es, der uns in einen solchen Zustand versetzte? Sind wir durch deinen Willen bestimmt, ewig von einem unaufhaltbaren Trieb zu einem Gute angespornt zu werden, welches wir nie finden? ewig eine Begierde in uns zu ernähren, deren Sättigung nirgends vorhanden ist? Gütiger, kommt dieses Uebel aus deiner Hand? 'Bist du die Quelle dieser Leiden?" (Das Dasein Gottes steht Jean Paul stets ausserhalb aller Skepsis.) Eine Gestalt erscheint nun dem träumenden Dichter und tröstet ihn mit den nothwendigen Schranken des endlichen Geistes, der Teleologie und propädeutischen Kraft des Irrthums und der künftigen Aufklärung im Jenseits: " $\mathrm{Du}$ forderst, gar nicht zu irren? So forderst du, dass Gott dich nicht hätte schaffen sollen. Entweder ein fühlloses Atom oder Gott hättest $d u$ 'werden müssen, um nicht zu irren. Du beklagst dich, dass du nur Mensch bist? so hat auch das Thier Recht zur Klage, dass es nur Thier ist, habe ich es, dass ich nur Seraph bin. Du beklagst dich über das, was du nicht hast und vergisst darüber den Dank für das, was du hast. . . Der Sterbliche würde 
seltner irren, wenn er mit dem zufrieden wäre, was er gewiss weiss; aber weil sein Geist keine Grenzen kennt, so setzt er Hypothesen an die Stelle der Wahrheiten und - irrt. . . Es ist nothwendig, es ist nützlich, dass wir gerade so viel Irrthümer als Wahrheiten haben. Mit Nacht ist des Allwissenden Rath umhüllt. Wir entdecken nur einzelne Spuren seines Plans und diese sind so weise, so erhaben, - sollen wir nicht denken, dass das, was wir nicht kennen, eben so weise, eben so erhaben sein werde? Glaube mir, Mitgeschöpf, jeder Irrthum ist mit in die unabsehliche Kette der Weltbegebenheiten eingewebt, seinen Nutzen entdeckt das blöde Auge des Endlichen nie, nur der, der Alles sieht, sieht auch ihn.... Reine Wahrheit sieht bloss der Alleinsehende; aber er hat auch Kraft dazu, weil er unendlich ist. Wer nur eine endliche Zahl Wahrheiten begreift, muss irren. 0 fühle ganz, Mensch, die Würde, ein Geschöpf zu sein, das Wahrheit erkennt, versink' in Entzücken, wenn sich dein Geist den Weg vorstellt, welchen er in tausend, tausend Jahren wird gegangen sein! Welch ein unabsehliches Feld von Wahrheiten wird dein wonnetrunkener Geist überschanen welche weitentlegene Gefilde im Reiche des Wahren werden sich deinen gierigen Blicken zeigen! . . Hier eure Welt, die ihr bewohnt, hat der Allvater nicht zum Ort bestimmt, wo ihr Wahrheit finden sollt; hier will er nur den Trieb in euch erwecken, sie zu suchen. Gerade euer Irrthum erregt den heissen Wunsch, zur Wahrheit zu gelangen." " . Ich erwachte. . . Ich bedauerte, dass es nur ein Traumbild war. Aber ich tröstete mich damit, dass nicht jedes nichtig sei. Vielleicht wird auch dieses erfüllt, vielleicht in dem Lande erfüllt, wo man nicht mehr träumt, nicht mehr um Träume - zankt."

Die Erörterung die mit Lessing'schen Ideen stark imprägnirt ist, endet also mit einem „Vielleicht“. Von der Universitït erwartete der frühreife Forscher eine Aufhellung seiner Zweifel und Unklarheiten, sogar eine Heilung seiner religiösen Skepsis. Darum liess er sich als Candidat der Theologie immatrikuliren. In letzterer Hinsicht enttäuschte ihn die Universitätswissenschaft; die Theologieprofessoren neigten meist zur Heterodoxie, und soweit sie positiv waren, wie Burscher, fanden sie die Verachtung Jean Pauls. Siehe 
darüber die Bricfe an Vogel 14. Sept. 1781 (Reimer 63, 195ff.). Dagegen brachte ihm das Universitätsstudium ein festes philosophisches System, dem er sich längere Zeit nit Entlusiasmus anschiloss.

\section{Die Universititsperiode.}

a) Jean Paul als Leibnizianer.

An der Leipziger Universität, wo er als Cand. d. Phil. u. Theol. am 19. Mai 1781 immatrikulirt wurde, hörte Jean Paul Logik, Motaphysik und Aesthetik bei Platner, Exegese bei Weber und Morus, Moral bei Wieland, Geometrie und Trigonometrie bei Gehler und englische Sprachlehre bei Rogler. (Brief an Vogel Nov. 1781. Reimer, 63, 208; in Wahrh. etc. 3, 132 steht statt Rogler Hempel.) Den tiefsten Eindruck machte auf ihn Platner. Er hält ihn für „einen der besten Philosophen Deutschlands". "Welches Glück für mich, sein Zuhörer zu sein!“ (Br. vom 17. Sept.). „Um Ihnen Platner ganz zu malen, müsst' ich er selbst oder noch mehr sein. Man muss ihn hören, man muss ihn lesen, um ihn bewundern zu können. Und dieser Mann, der so viel Philosophie mit so viel Annehmlichkeit, so viel gesunden Menschenverstand mit so grosser Gelehrsamkeit, so viel Kenntniss der alten Griechen mit der Kenntniss der neueren vereinigt, und als Philosoph, Arzt, Aesthetiker und Gelehrter gleich gross ist und eben so viel Tugend als Weisheit, eben so viel Empfindsamkeit als Tiefsinn besitzt - dieser Mann ist nicht nur dem Neid jedes schlechten Kopfes, sondern der Verfolgung der mächtigen Dummköpfe und der heimlichen Verleumdung ausgesetzt. . . Er wurde einmal vor das Consistorium zu Dreslen gefordert, um sich wegen der Beschuldigung des Materialismus zu. verantworten. Wenn man ihm etwas weniger" (am wenigsten) „Schuld geben kann, so ist es dieses; er ist der erklïrteste Feind des Materialismus; man muss seine Aphorismen nicht gelesen, nicht verstanden haben, um es nicht zu wissen. Doch es war ein Consistorium, dieses hat das Recht, mit mehr Ehre dumm und mit mehr Heiligkeit boshaft $z u$ sein als andere Menschen. . Kaufen Sie seine philosophischen Aphorismen! Sie treffen in diesen die Ieibnizische Philosophie im körnigsten Aus- 
zug und eine Menge Erläuterungen und Bemerkungen in gedrängter Schreibart an." Br. v. Nov. 1781 an Vogel.

In den Briefen an Vogel aus Leipzig finden sich auch philosophische Excurse, so gleich im ersten vom 27. Mai der Gedanke:

„Ueber Ihr Nichts, wovon Sie mir neulich sagten, habe ich nachgedacht. Der Gedanke ist schön; die Einbildungskraft verliert sich darin. Allein ich glaube, Ihnen beweisen zu können, dass es gar kein absolutes Nichts geben kann. Schon in dieser Rücksicht nicht: weil Gott überall ist - und wenn wo ein absolutes Nichts wäre, so würde Gott nicht sein. Verstehen Sie das Nichts so: ein Ort, wo kein Körper existirt, so wollte ich deutlich beweisen, dass überall Körper sein müssen - und dass der Satz in der Metaphysik, Alles Ausgedehnte hat Grenzen' so wahr nicht ist, als es scheint. Es kommt auf Sie an, ob ich's einmal thun soll." (Wahrscheinlich sind auch hier Leibnitz'sche Gedanken von der Idealität des Raums im Hintergrund, durch Platner angeregt.) Im Br. v. Nov. 1781: „Sie wollen mirs zugeben, dass der Mensch im künftigen Leben seine Erdsprache nicht mehr habe. Das ist leicht zu beweisen: 1. Wir haben denselben Körper, also dieselben Sprachorgane nicht mehr; wir müssen" (ich vermuthe: müssten) "in die andere Welt auch unsere Ohren mitbringen und unsere Luft da wehen lassen. 2. Die Möglichkeit, andere durch Zeichen von unseren Gedanken zu unterrichten, schränkt sich nicht auf die Sprache allein ein: es sind tausend Möglichkeiten, uns den anderen verständlich za machen; jch sehe also nicht ein, warum wir die jetzige überallhin setzen wollen. 3. Was soll denn unsere Sprache in der andern W'elt? wo sollen die Benennungen der jetzigen Dinge für die Dinge gelten, die wir nicht kennen? Der Himmel müsste ganz alle die Geschöpfe, die Gesetze, die Bescháffenheiten, die Laster und Tugenden, die politische und philosophische Verfassung unserer Welt haben, um unsere Sprache zu haben. Wir werden aber dort die Dinge nicht sehen, die wir hier sahen, und Dinge sehen, die wir hier nicht sahen; wir werden unsere alte Sprache vergessen und eine neue lernen müssen." (Der Schluss ist offenbar nicht zutreffend; neue Objekte involviren keine neue Sprache.) „Und was sollten denn die Völker im Himmel mit ihren 
Sprachen anfangen, die nur als ein verwirrtes Getön zusammenklingen? Und wahrlich, wenn dies Alles zugestanden würde, man würde sich doch gewiss seiner vorigen Erdensprache schämen, man wïrde ihre Mängel einsehen und die Zeit bedauern, die durch ihr Studium nützlichen Geschäften ist geraubt worden." 63, 204. 5.

In Leipzig hielt Jean Paul ein "Tagebuch meiner Arbeiten" gewissermassen als Fortsetzung der „Uebungen im Denken“, von dem zwei Hefte aus August und September 1781 vorliegen. Daraus entnehmen wir folgende Gedanken:

"Vielleicht ist unser Jahrhundert tolerant gegen Meinungen und intolerant' gegen Handlungen. Man darf jede Wahrheit frei sagen, aber 'man darf nicht jede Tugend unverspottet ausüben. Wir leiden jede Art Freigeisterei, nur nicht alle Arten von Heiligen. Wir haben das Joch der Systeme abgeschüttelt und die Bande des Wohlstandes mit doppelter Strenge geknüpft. Ich möchte heutzutage lieber Epikur als Diogenes oder lieber Atheist als Schwärmer sein." (Eine Umschreibung des Goethịschen: Im Praktischen ist doch niemand tolerant.)

„Dienstag; 28. August. Man sollte uns nicht. Philosophie, sondern philosophiren lehren, uns nicht gewöhnen, Wahrheiten einzusehen, sondern sie zu erfinden; man sollte überhaupt mẹr die Geschichte der Philosophie als sie selbst vortragen. Nichts ist nöthiger als Selbstdenkèn, nichts ist schätzbarer und vielleicht auch nicht schwer zu erwerben. . Man erschwert diese Arbeit doppelt, weil man diese Trägheit nicht nur nicht unterdrückt, sondern sie noch verstärkt. In unserer Jugend sollen wir die Behältnisse des, Aberglaubens, der Lüge werden, womit ein Geschlecht das andere beschenkt; man bahnet in der Seele den. Irrweg zu tief, als dass sie einmal, wenn sie stärker geworden, nur die Möglichkeit eines andern Wegs muthmassen, noch weniger den Muth, einen andern zu betreten, haben könnte; man macht aus uns Maschinen. Der Theolog macht den Anfang, der Philosoph setzt es fort: und unșere eigne Trägheit vollendet es." Obwohl diese Aeusserungen bereits einige Skepsis zeigen, so zeigt sich Jean Paul in jener Zeit doch als ein entschiedener Anhänger des Leibniz-Platnerschen Idealismus. Sehr interessant sind hiefür, die Aufsätze aus 1781: „Etwas über. 
den Menschen" und "Etwas über Leibnizens Monadologie" (bei Reimer Bd. 63, S. 17-43 und 52-54.)

Der erste ist stark von Jerusalems „Betrachtungen über die vornehmsten Wahrheiten der Religion" 1868 beeinflusst; Citate aus diesem Buch im Excerptenheft von 1778 I. S. 207 stimmen mit deu wichtigsten Stellen des Aufsatzes fast wörtlich überein. Weiteren starken Einfluss übte Pope, dessen sämmtliche Werke 1780 unter den gelesenen Schriften angeführt sind. (Pope hat bekanntlich einen mit dem Jean Paul'schén Aufsatz gleichnamigen Essại geschrieben.) Wie Pope hält Jean Paul die Licht- und Schattenseiten der meuschlichen Natur grell einander gegenüber, um dann das Facit der demüthigen Selbstbescheidung sowohl in der Eigenschätzung als in der fremden Beurtheilung zu ziehen. Mit Pope, den er S. 32 der Gesammtausgabe citirt, lässt er aber doch dem moralischen Optimismus die Oberhand. Die Sünden und Irrthümer seien nur die Kehrseite der menschlichen Vollkommenheiten: „Wenn wir weniger bös sein wollten, so müsst' uns der Schöpfer mit weniger Anlage zur Tugend geschaffen haben . . Wir könnten uns nicht uber den Engel erheben, wenn wir nicht unter das Thier herabsinken könnten." Psychologisch interessant ist vor Allem der schon berührte enge Anschluss an Leibniz, dem herrschénden Philosophen jener Zeit, mit dem Jean Paul nicht nur durch seine Lektüre, sondern besonders auch durch seinen Lehrer Platuer innig, verwachsen war. Die sinnliche Erkenntniss sei trügerisch, aber in diesem Betrug liege der Same der Wahrheit. „Wir lösen das vermischte Licht der Sinne durch das Prisma der Vernunft in seine einfachen Farben auf . . Dies ist nicht wunderbar, dass er (der Mensch) die Welt durch das gefürbte Glas seiner Sinne betrachtet; dies ist nicht unerklärbar, dass der Allweise selbst diese Täuschung zu seinem Nutzen veranstaltet hat; allein dies ist wunderbarer" (uicht "wunderbar", wie Förster druckt), "dass er noch neben diesem Glas einen Blick auf die wahre Gestalt der Dinge werfen kann; dies ist unerklärbarer" (nicht „unerklärbar", wie in der gedruckten Ausgabe), „dass er die Täuschung wahrnimmt, in welcher er sich befindet und einem Theil der Irrthümer widersteht, die man ihm aufdrängen will. Leibnizens 
Mo nadologic hebt den Vorhang der '/ukunft auf und eröffnet dem licht der Ewigkeit den '/ugang in die sterblichen Augen; sie sagt dem Nenschen das, was sie als Engel erfahren sollten, sie macht uns gross in der Hülle und $z u$ wunderbaren Mittelgeschöpfen entfernter Welten."

"Die Einbildungskraft des Menschen baut aus Bruchstücken dieser Welt eine neue zusammen; sie ist die Malerin von Meisterstïckon, lazu die Sinne blos die Farben geliehen haben. Dieses ist nicht wunderbar; allein dieses ist es vielleicht mehr, dass sie nicht das Endliche, sondern das Unendliche malt und in den engen Bezirk des menschlichen Gehirns gleichsam das verkleinerte Bild der Unermesslichkeit aufstellt. Man hat Unrecht, zu sagen, dass wir nur das Endliche denken können; im Gegentheil: wir können uns nur vom Unendlichen einen Begriff machen. Wir glauben etwas Endliches zu denken, wenn wir blos den Absat\%, den Theil einer unendlichen Stetigkeit denken. Dies ist paradox und unerklärbar, sowie überhaupt unsere Einbildungskraft eine dunkle Werkstätte geheimer Kräfte ist.". S. 35. 36.

In einer Anmerkung nennt Jean Paul Platner den Ersten, der dies bemerkt habe und fügt bei, was Foerster übergeht: „Da man das nicht geben kann, was man nicht hat, so kann ich diesen vortrefflichen Mann nicht loben, aber ich kann ihn bewundern." Der Gedanke, dass die Unendlichkeitsidee die Priorität vor der Erkenntniss des Endlichen als Endlichen habe und all unseren Gedanken und Bestrebungen zu Grunde liege, hat mächtigen Eindruck auf Jean Paul's ideal angelegte Natur gemacht und bildet in seinen Schöpfungen fast den leitenden Grundton. Urheber des Gedankens dürfte übrigens Descartes sein (cf. Epist. I, 119 oder Resp. 5. contra Gassendi.) Wenn die positive Idee des unendlich Vollkommnen nicht als Massstab und Typus vorhanden wäre, könnten wir nach Descartes die Vorstellung unserer eigenen Unvollkommenheit nicht bilden, so wenig als die der Blindheit ohne die des Sehens. Aehnlich bemerkt auch Jean Paul im Hesperus (S. 546 der Hempel'schen Ausgabe), der Mensch könne, wie Platner mit Recht sage, eigentlich nur das Endliche nicht denken. (Die 
Erörterung dieses Themas siehe in meinem Buch: „Jean Paul und seine Bedeutung f. d. Gegenwart" S. 154 ff.).

Noch ist zu bemerken, dass in der Abhandlung der Gottesund Unsterblichkeitsgedanke kräftig betont ist, nur das Wie? der Unsterblichkeit liege im Dunkel.

Der Aufsatz über Leibnizens Monadologie ist ein warmer Panegyrikus des Schülers für seinen Meister; er schliesst: „Leibnitz braucht keine Schüler auf der Erde; aber er kann Lehrer sein in der andern Welt. Vielleicht hat er in derselben mehr Engel zu Bewunderern gehabt als Menschen in dieser und vielleicht erntet er erst die Lobeserhebungen der Sterblichen ein, wenn sie selbst unsterblich sind." Eine weitere Arbeit aus dem Jahr 1781 ist der Aufsatz "Vergleichung des Atheismus mit dem Fanatismus" (bei Reimer 63, 43-46.) Der natürliche Gottesglaube im Sinn des Deismus wird als die richtige Mitte der beiden Extreme bezeichnet; bei der Beleuchtung beider fällt aber viel günstigeres Licht auf den Atheismus als den "Fanatismus".

b) Die Zeit der philosophischen Skepsis.

Die erste Zeit seiner ungetrübten philosophischen Ueberzeugung sollte nicht lange dauern. Mit Wehmuth erinnerte sich der spätere Dichter dieser Periode. „Selige, selige Zeit! Du bist schon lange vorbei! 0, die Jahre, worin der Mensch seine ersten Gedichte und Systeme lieset und macht, wo der Geist seine ersten Welten schafft und segnet, und wo er voll frischer Morgengedanken die ersten Gestirne der Wahrheit kommen sieht, tragen einen ewigen Glanz und stehen ewig vor dem sehnenden Herzen, das sie genossen hat und dem die Zeit nachher nur astronomische Ephemeriden und Refraktionstabellen über die Morgengestirne reicht, nur veraltete Wahrheiten und verjüngte Luigen. 0, damals wurde er von der Milch der Wahrheit wie ein frisches durstiges Kind getränkt und grossgezogen; später wird er von ihr nur als ein welker skeptischer Hektikus kurirt! Aber du kannst freilich nicht wiederkommen, herrliche Zeit der ersten Li e be gegen die Wahrheit und diese Seufzer sollen mir eben uur deine Erinnerung wärmer geben; und kehrst du wieder, so geschieht es gewiss nicht hier im tiefen, niedrigen Grubenbau des Lebens, 
wo unsere Morgonröthe in den Goldflämmlein auf dein Goldkies besteht und unsere Sonno im Grubenlicht - vein, sondern dann kauns geschehen, wenn der Tod uns aufdeckt und den Sargdeckel dos Schachtes von den tiefen blassgolben Arbeitern wegreisset, und wir nun wieder wie erste Menschen in einer neuen, vollen Ercle stehen und unter einem frischen, unermesslichen Himmel!“ (Titan, gegen Schluss des 25. Kap.)

Schon in den "Bemerkungen über uns närrische Menschen" $(62,1 \mathrm{ff}$.$) von den Jahren 1782$ und 1783 malt sich eine zunehmonde Verzweiflung an der Möglichkeit sicherer Erkenntniss. Am 16. August 1782 schreibt er: Zur Unbeständigkeit bin ich bestimmt, am meisten zu der der Meinungen. Nicht zwar unterjochen alle Bücher meine Ueberzeugung, aber doch manche treiben sie in die Enge; einige unterwerfen sie sich ganz und alle lassen an ihr Nerkmale ihrer Macht, wenigstens auf einige Zeit zurück." (Es ist wohl zu beachten, dass Jean Paul die Beherrschung durch Theorien als lästige Sklaverei empfindet.) „Doch mit Vorbeigehung dieser Bemerkung will ich zur Geschichte meines Glaubens kommen. Sie ist also Geschichte und kein Räsonnement darüber. Dass auch meine Ueberzengung durch die Macht der Erziehung gemisshandelt, dass auch in mein Gehirn durch wohlthätige Hände die Schreckbilder des Aberglaubens gedrückt worden, ist, leider! nur zu wahr. Und eben dieser fromme Missbrauch meiner kindlichen Leichtgläubigkeit ist schuld an dem beständigen Widerspruch meiner jetzigen Meinungen, die mit Mühe dem Widerstand der Gewohnheit stohen und die dann doch unterliegen, wann, von ihnen beschützt zu werden, mein Glaube sie in Sold genommen. Er ist schuld an dem Glanze, mit welchem der alte Unsinn unsere Vernunft blendet; schuld an den Unruhen; die oft jede Veränderung unserer Meinung verbittern und wird schuld sein an den Unruhen, die in der Todesstuncle den Unsinn an der fallenden Vernunft rächen und dem Aberglauben den Sieg noch vor dem Siege des Todes versichern werden." (62,5. Bezieht sich stets auf die erste Berliner, bei Reimer erschienene Gesammtausgahe, die allein den Nachlass enthält.)

17. Februar 1783. "Was ist das Leben? Ich wollt', ich 
wüsste es nicht; ich wollte, jene glückliche Selbstvergessenlieit des Wilden wäre mir zum Loose zugefallen, so fänden meine Leiden vicht den Kopf, sondern nur. die Sinne zum Eingang offen. Ich wollte, ich wäre recht weise oder gar nicht. Gebt mir die Kälte des Stoikers oder die Empfindung des Aristipp. Die Mitte zwischen beiden macht mir das Leben verhasst. Der unaufhörliche Bürgerkrieg meiner Gedanken und Empfindungen ermüdet meine Begierde nach Glückseligkeit. Da bin ich; sehe hinüber an die nebligen Ufer der Kindheit (des einzigen Alters, wo der Mensch glücklich ist, weil er - nur ein halber Menșch ist) und sehe schöne Träume, deren Verlust meine Weisheit ist. Dort war ich glücklich; denn die Hoffnung spielte noch wie ein Kind mit meinen Wünschen in jenem Alter, dessen Beschützung die fromme Mutter Engeln überlässt. Jetzt bin ich nicht glücklich; denn wenn ich es bin, so steigt im Hintergrund das Gespenst der Furcht oder der Vernunft oder des Ekels herauf, wächst mit seinen Gliedern bis an den Himmel - und nun stürzt der fürchterliche Koloss über meine Empfindung her und wird der Grabhügel meiner Freude. . . Warum hört mein Herz so auf, für meine Empfindungen zu schlagen? . . Dann kömmt . . die Kälte des Verstandes, die von dem noch kahlen Baume der Freude das letzte gelbe Blättchen abschüttelt; da erscheint das Gerippe der Abstraktion und schwingt unter den gebückten Bäumen die hungrige Todessense. Wohlan, so will ich mich mit dürrem Heu füttern. Mein . Herz mag nur meinen Adern, aber nicht meinen Freuden dienen; jch will mich in die kalten Arme der runzlichen Matrone, der Weisheit, werfen und will die Freude nicht mehr küssen, sondern nur - anatomiren. - Aber wo ist denu die Wahrheit, zu der ich vor dem Ekel fliehe? Wo ist sie? Ich sehe überall ihre Altäre, aber nicht sie selbst. Vielleicht sind ihre Priester glücklicher, aber ich bin nur desto unglücklicher. Ein Skeptiker muss ich sein, nicht weil ich einen grossen, sondern weil ich einen kleinen Verstand habe. Widerspricht nicht ein Scharfsichtiger dem andern? Der cine hält jene entfernte Gestalt für einen Baum, der andere für einen Menschen. Wem soll ich glauben? Etwa dem, dessen Ausspruch meine eignen Augen beifallen? 0, ich sehe dort weder 
einen Baum, noch einen Menschen, sondern nur einen schwarzen Punkt. Nun weiss ich nichts. Gebt mir Leibnizens Verstand, so irre ich doch noch. Ich habe aber nur den meinen; ich kann nicht einmal irren, sondern nur nachbeten. Nein, ich mag keinen. Ich will meine Augen zudrücken und meinen Blick in die Nacht zwischen meine Augenlider und die Sehnerven stürzen. Da soll er gefesselt bleiben. . . Also ohne Herz für die Freude, ohne Kopf für die Wahrheit, ohne Kraft, den Verlust von beiden zu ertragen - was bin ich dann? 0, ich fühle die Antwort. . . Ich bin das, zu was mich der Tod nicht $z u$ machen braucht und zu was mich mein vergangenes Nichtsein nicht machte" (indem ich $\mathrm{zu}$ einem so öden Leben erweckt wurde). 62, 8-10.

„Die besten Systeme sind mit den falschen verwandt. Es giebt schwerlich einen wahren Satz, um den nicht verwandte Bastarde stehen. Um den Stoizismus stehen Quietismus und Fohismus; wie nahe grenzt die Enthaltung des Mönchthums an das Christenthum! Dies giebt uns die Regel, da, wo wir einen wahren Satz so weit treiben, dass er mit aller unserer Empfindung und Denkart zu kriegen anfängt, zu stutzen und zurückzukehren.“ S. 31 .

(Schluss folgt.) 